\title{
Kernos
}

Revue internationale et pluridisciplinaire de religion grecque antique

8| 1995

Varia

\section{F. Graf, Greek Mythology. An Introduction}

\section{Vinciane Pirenne-Delforge}

\section{(2) OpenEdition \\ Journals}

\section{Édition électronique}

URL : http://journals.openedition.org/kernos/615

DOI : 10.4000/kernos.615

ISSN : 2034-7871

\section{Éditeur}

Centre international d'étude de la religion grecque antique

\section{Édition imprimée}

Date de publication : 1 janvier 1995

Pagination : 306-307

ISSN : 0776-3824

\section{Référence électronique}

Vinciane Pirenne-Delforge, « F. Graf, Greek Mythology. An Introduction », Kernos [En ligne], 8 | 1995, mis en ligne le 12 avril 2011, consulté le 24 septembre 2020. URL : http://journals.openedition.org/kernos/ 615 ; DOI : https://doi.org/10.4000/kernos.615 
quelques réussites au IVe siècle comme celles de Libanios, Grégoire de Nazianze et surtout Augustin; les références constantes à des définitions modernes dans les différentes communications montrent a contrario ce que ce moyen d'expression a d'incongru, de toujours exceptionnel dans le monde antique.

On comprendra dès lors pourquoi la conclusion de S. Follet dresse un constat des difficultés rencontrées par l'autobiographie, constat qui fait écho aux problèmes méthodologiques posés au début du colloque par $\mathrm{M}$. Trédé : s'interroger sur l'application du terme consiste à poser un regard moderne sur les œuvres antiques, à prendre la mesure moins d'une similitude que d'un écart. Ce n'est pas l'un des moindres mérites de cet ouvrage que de nous inviter à l'exploration toujours problématique de cet écart.

Marie-Pierre NOËL

(Université de Paris IV-Sorbonne)

Fritz Graf, Greek Mytbology. An Introduction. Translated by Thomas Marier. Baltimore, The Johns Hopkins University Press, 1993. 1 vol. $15 \times 22 \mathrm{~cm}$, XII +240 p., 11 fig. ISBN : 0-8018-4657-9.

L'original allemand de cet ouvrage date de 1985 et a connu une deuxième édition en 1987. Après une traduction italienne, en voici la traduction anglaise. Je pense qu'il convient néanmoins d'en parler encore dans la mesure où il s'agit, à ce jour, de l'une des meilleures approches de la mythologie grecque, entendue à la fois comme corpus de récits et comme étude de ce corpus, depuis l'Antiquité jusqu'à l'actualité scientifique la plus immédiate.

Dans l'introduction, F. Graf tente de donner les éléments permettant d'esquisser une définition de la notion problématique de «mythe »: irréductible à un genre littéraire particulier, le mythe est un récit traditionnel dont la capacité d'adaptation est signe de vitalité. Le premier chapitre aborde ensuite les linéaments de l'étude scientifique moderne des mythes avec, notamment, deux figures trop souvent oubliées des hellénistes : Christian Gottlob Heyne et Gottfried Herder. De la fin du XVIIe au XIXe siècle, F. Graf nous emmène, en un parcours clair, lucide et plein de sympathie, sur les traces de ces pionniers qui ont cherché à comprendre les mythes : $\mathrm{B}$. de Fontenelle, F.J. Lafitau, N. Fréret, G. Vico, D. Hume, F.G. Welcker, F. Creuzer et le courant romantique, dont F.W.J. Schelling trop souvent oublié, K.O. Müller et la revalorisation de l'histoire, J.W.E. Mannhardt et les folkloristes allemands, J.G. Frazer et l'école anthropologique anglaise, pour ne citer qu'eux. Et de Fontenelle à Frazer, il existe davantage de constantes que de différences : 1) expliquer un mythe, c'est toujours en trouver l'origine, souvent conçue comme une réponse de l'homme à son environnement ou à un événement historique, au divin ou à lui-même; 2) les étrangetés sont dues à un stade enfantin de l'esprit humain; 3) la présence d'éléments similaires en des lieux différents 
provient soit de la dispersion d'un centre commun, soit d'un développement spontané.

Le deuxième chapitre parle du XXe siècle et des nouvelles approches dans l'étude du mythe, profondément redevables des interprétations du siècle précédent : depuis J.E. Harrison, C.G. Jung, E. Durkheim, B. Malinowski, V. Propp, jusqu'à G. Dumézil, C. Lévi-Strauss, J.-P. Vernant, A. Brelich, W. Burkert, R. Barthes et C. Calame, entre autres.

Après cette vaste excursion au pays des interprétations modernes et contemporaines, le troisième chapitre nous replonge dans la matière même du mythe grec, et plus particulièrement dans ses relations avec l'épopée, assorties de la difficile question des « origines » et donc de la matière « pré-épique ». Viennent ensuite, avec le quatrième chapitre, les récits de l'origine du monde et des dieux, la Théogonie d'Hésiode et son arrière-plan oriental, la poésie cosmogonique postérieure et la réflexion philosophique sur les données du monde physique. Le cinquième chapitre parle des mythes " cultuels ", autour des sanctuaires et des fêtes, et repose le problème des relations entre le mythe et le rite autour des récits étiologiques. Les trois derniers chapitres abordent respectivement le mythe conçu comme «histoire» par les Grecs, son utilisation dans le chant choral et la tragédie, et la réflexion critique des Anciens sur leurs propres mythes.

Chaque donnée, ancienne ou moderne, est envisagée avec sympathie, dans un contexte qui lui donne un sens, notamment pour l'actualité de la recherche qui est pour beaucoup l'héritière d'un passé rappelé dans ses aspects les plus divers. À lire et à méditer pour combattre tout «terrorisme » intellectuel, toute vision exclusive. Comme l'écrit Ken Dowden dans une autre introduction à la mythologie grecque, we live in syncretistic times!

Vinciane PIRENNE-DELFORGE (Université de Liège)

Pierre HaDot, Plotin. Traité 9 (VI, 9). Introduction, traduction, commentaire et notes, Paris, Ed. du Cerf, 1994, 1 vol. 12,5 x 19,5 cm, 252 p. (Coll. Les écrits de Plotin publiés dans l'ordre chronologique sous la direction de Pierre Hadot ). ISBN : 2-204-05013-X. Prix : 150 FF.

C'est le 3 e volume paru de cette précieuse collection dont l'A. assure la réalisation avec une persévérante assiduité (pour les Traités $38(V I, 7)$ et 50 (III, 5) déjà publiés, cf. Kernos, 1 [1988], p. 253, et 5 [1992], p. 349); il est dédié à la mémoire de H.-R. SCHWYZER. Intitulé Du Bien ou de l'Un, un titre sans doute donné par Porphyre, le traité 9 est le dernier dans l'édition que le disciple a donnée des Ennéades, mais il compte en fait parmi les premiers que Plotin ait écrits. Il est consacré au Principe suprême et représente donc le sommet de sa théologie à dominante négative : aucun nom, pas même l'Un, ne convient pour dire cette Réalité suprême qui transcende l'Intellect. De l'Un, il n'est nulle connaissance, nulle science; on ne peut le saisir que dans une 